Short Communication

\title{
Situation-specific cognitive behavioural self-therapy for erroneously suspected allergy or intolerance to a food: a short self-assessment tool
}

\author{
Rebecca C. Knibb**1,2 and David A. Booth ${ }^{2}$
}

${ }^{1}$ Psychology, School of Science, University of Derby, Kedleston Road, Derby, DE22 $1 G B$

${ }^{2}$ Nutritional Psychology Research Group, Psychology-in-Medicine Research Consortium, University of Birmingham, Edgbaston, Birmingham B15 2TT, UK

*Corresponding Author. Email address: R.C.Knibb@derby.ac.uk (Rebecca Knibb)

[Acknowledgements footnote]

This research project was funded by MAFF, London. The Principal Investigators were Professors D.A. Booth (Psychology) and I.W. Booth (Child Health), with Dietetics Research Consultant Dr A. Macdonald. The Research Executives were Drs R.C. Knibb (Psychology) and A. Armstrong (Nutrition) and Mrs R.G. Platts. Dr Knibb is now Reader in Health Psychology, Psychology, School of Science, University of Derby.

\section{Research Highlights}

- A short questionnaire assesses recall of an adverse symptom following ingestion of a food.

- Realistic thinking and appropriate action are encouraged in accord with research evidence regarding the answers.

- This therapeutic tool can be used by the person who suspects food intolerance or by a professional advisor 


\section{ABSTRACT}

The recall of personal experiences relevant to a claim of food allergy or food intolerance is assessed by a psychologically validated tool for evidence that the suspected food could have caused the adverse symptom suffered. The tool looks at recall from memory of a particular episode or episodes when food was followed by symptoms resulting in self-diagnosis of food allergy or intolerance compared to merely theoretical knowledge that such symptoms could arise after eating the food. If there is detailed recall of events that point to the food as a potential cause of the symptom and the symptom is sufficiently serious, the tool user is recommended to seek testing at an allergy clinic or by the appropriate specialist for a nonallergic sensitivity. If what is recalled does not support the logical possibility of a causal connection between eating that food and occurrence of the symptom, then the user of the tool is pointed to other potential sources of the problem. They are also recommended to investigate other remedies rather than avoidance of the food that had been blamed.

Keywords

food allergy

intolerance

self-diagnosis

assessment tool. 


\section{Erroneously blamed foods}

Unpleasant symptoms are blamed on foods by a substantial minority in European and North American populations. Meta-analysis has found that up to 35\% of the population believes themselves to be allergic or intolerant to food (Rona, Keil, Summers et al., 2007). Yet objective tests confirm only a small proportion of these complaints (Rona et al., 2007; Young et al., 1994). Therefore it would benefit many members of public and overloaded allergy clinics to have a scientifically validated and constructed questionnaire tool that could be self-administered (in paper format or online) or used as the basis of an interview by practitioners qualified to follow-up testimony to a potential food sensitivity. The tool in the Appendix was published in a new journal based in a research institute and is only available online via a link to an academic personal page. We are therefore reproducing it in the peerreviewed multidisciplinary literature with an updated scientific background.

\section{The evidence base}

Between 1997 and 1998, 300 complainants of food-induced "allergy or intolerance” were recruited from the community by randomised mailings to electors in the city region of Birmingham in the English Midlands (Knibb, Armstrong, Booth et al., 1999a). Research evidence at that time (e.g. Young et al., 1994) suggested that up to 20\% of those selfdiagnosing food allergy or intolerance were in error in believing that their symptoms arose from ingestion of food. One of the important findings was that the presumably misattributed symptoms were not usually "psychological” or "psychosomatic” (Knibb et al., 1999a), as had been widely stated in this field. For example, in the UK food intolerance had been defined as "an unpleasant reaction to food which is caused by emotions associated with the food rather than by the food itself” (Royal College of Physicians and British Nutrition Foundation, 1984). Follow-up questionnaires to these recruits and to other research volunteers who did not blame foods for their illnesses detected few differences in anxiety or depression between those who supposed that they were food allergic or intolerant and non-allergic controls (Knibb et al., 1999a).

Rather, we concluded, "false food allergy" in the community is real suffering with a physical basis (whether or not mediated by the immune system) and there was nothing unreasonable in the suspicions elucidated by detailed responses to structured interview. Moreover, many of the interviewees had indeed been advised by their doctor to look at their diet for a possible cause of their symptoms (Knibb et al., 2000). Health pages, leaflets and 
broadcasts of higher or lower reliability alert the general public to the serious reactions that some children or adults have to a great variety of foods and drinks. There are books for the lay reader that go through the scientific evidence for adverse effects from common dietary constituents (e.g., Emsley \& Fell, 2000).

None of this, however, provides individuals with a basis for judging whether or not a symptom that can come from eating a food, has or has not in fact been caused by that food in their case. There are so many possibilities in the diet, and of other influences on such a symptom (such as airborne allergens or bacteria causing food poisoning), that even an appropriately specialised practitioner often cannot make a reliable diagnosis without blind physical testing. Eating and drinking are so frequent and involve so many combinations of chemically complicated materials that some dietary constituent or another is liable to be consumed before the onset or exacerbation of symptoms or an illness from any cause. Thus even a highly intelligent, very careful and well informed member of the public is liable to make the mistake of suspecting an innocent food of generating the adverse symptom. The imputation of hypochondria and worse to millions of ordinary people is in many cases unfounded.

Indeed, the great prevalence of misperceived food allergy or intolerance illustrates the fact evident in other areas of public health (Booth, 1999; Booth \& Platts, 2000) that the communication of nutrition information on the basis only of general biochemical and epidemiological evidence is not only of little use but can be counterproductive. Advice on healthy eating patterns and other complex choices must be personally tailored from direct evidence provided by the individual. Here psychological science can be as useful as medical science. We applied cognitive psychologists' research findings on memory to interviewees’ attempts to recall personal experiences of the symptom in question occurring shortly after consumption of the blamed food (Knibb, Booth, Armstrong et al., 1999b). Memory for an actual occasion when eating the food was followed by the symptom could be distinguished from the belief in an allergy or intolerance based only on the theoretical knowledge that such a food can give rise to the symptom in question.

That set of cognitive performance criteria for the actuality of a food-symptom episode was supplemented by criteria based on the logic of evidence for causal connections of any type (Booth et al., 1999; Knibb et al., 1999b). These causal criteria are of two sorts. Causal contingency requires that the recalled co-occurrence of food and symptom was unlikely to be mere coincidence arising from frequent occurrence of either the food or the symptom. The contiguity requirement is that the symptom arose sufficiently soon after the food had been 
eaten for some sort of cause-effect relationship to be plausible. The criteria of contiguity were however applied to the interview data without reference to current knowledge of pathophysiological mechanisms specific to that food and symptom (Knibb et al., 1999b).

In nearly all cases, interviewees whose food-symptom recall met most of the criteria of actuality, contingency or contiguity could be assigned to that same category by their answers to just one of the criteria for actuality, contingency or contiguity. These findings (Booth et al., 1999; Knibb et al., 1999b) therefore enabled the construction of a short questionnaire to screen for personal evidence that the symptom could have been caused by the blamed food and so to feed back advice on what to do about the symptom, tailored by the individual respondent's answers. One version of the resulting evidence-based self-care advice tool accompanies this paper.

\section{Structure of the tool}

The first two questions within this advice tool are designed to identify those people who are recalling an actual episode when the symptom followed eating the food. In our community sample, $38 \%$ of interviewees ( $24 \%$ of food-symptom reports) would have been able to give a precise answer to both of these two questions for at least one food they blamed for a symptom. Such people should be advised to go to a hospital clinic for further investigation if the symptom and/or the food are important and avoiding the food results in a poorer quality of life, psychological distress or inadequate nutritional intake.

Those who cannot answer both of the first two questions precisely are asked to go on to questions 3a, 3b and 3c in the tool. Answering these helps the tool-user to consider other possible causes of the food-attributed symptom and whether the co-occurrence of food and symptom was mere coincidence. Among those of our interviewees who would have been referred to this part of the questionnaire, a further $24 \%$ (29\% of food-symptom reports) had reason to believe that the co-occurrence of food and symptom was not a coincidence. These people should also be advised to ask their GP to refer them for further investigation by an appropriate specialist. Table 1 shows the percentages of interviewees who were classified as perhaps erroneously suspecting food caused their symptom.

The reasoning offered after answering these questions identifies to the tool-users where they have a solid case against the food or where the attribution of the symptom to the food is likely to have been an understandable mistake. A small proportion of those in the community who believe that they have a food allergy or intolerance may have serious emotional problems with eating what they perceive to be a harmful food. Such people are 
liable to find this tool no more persuasive than any other reasoning or authoritative instruction. Where a powerful emotional reaction is discrete to the food, a clinical or health psychologist could be consulted about the possibility of therapy of the kind that is effective in reducing other sorts of anxieties, panic or phobia. Many of our interviewees showed no aversion to the food that they feared or professed to avoid, i.e. they did not state that they feared the food or had come to dislike the taste or have any feelings of disgust towards the food (Knibb et al., 2001). Nevertheless, if a wholesome food has become disliked, “extinction” therapy may be applicable. Where the disruptive emotion about a food is part of a more general problem about eating and perhaps about other parts of life, these wider difficulties should be addressed by the appropriate evidence-based therapeutic approach.

\section{Use of the tool}

Copies of the accompanying tool may be distributed to members of the public by individual professionals, commercial or not-for-profit organisations or the media. However, the authors have retained copyright because the tool is valid only when used as a whole and so permission will not be given to reproduce a subset of the questions. Nevertheless, the layout of the material and the exact wording of the advice might be adjusted, so long as the authors review the edited version for any conflict with the psychological evidence. The tool may also be adjusted for use online.

Requests to reproduce the tool also permit the authors to seek opportunities to assess its impact on individual consumers and on relevant aspects of the food supply and the health services. Ideally a particular paper or interview version of the tool should be validated prospectively against physical diagnosis of a food intolerance in an unbroken series of users. 


\section{References}

Booth, D.A., Knibb, R.C., Platts, R.G., Armstrong, A.M., Macdonald, A., \& Booth, I.W. (1999). The psychology of perceived food intolerance. Leatherhead Food RA Food Industry Journal 2, 325-334.

Booth, D.A. (1999). Evidence-based reduction of obesity: identification of a subculture's least fattening eating patterns. In: Workshop of IUNS Committee on Food Habits \& Nutrition, International Congress of Nutrition, Montreal. Appetite 32, 80-85.

Booth, D.A., \& Platts, R.G. (2000). Tool for assessing and reducing an individual's fat intake. Appetite 34, 107-108.

Emsley, J., \& Fell, P. (2000). Was it something I ate? Food intolerance: what causes it and how to avoid it. Oxford University Press.

Knibb, R.C., Armstrong, A.M., Booth, D.A., Platts, R.G., Booth, I.W., \& Macdonald, A. (1999a). Psychological characteristics of people with perceived food intolerance in a community sample. Journal of Psychosomatic Research 47, 545-554.

Knibb, R., Booth, D.A., Armstrong, A., Platts, R., Macdonald, A., \& Booth, I.W. (1999b). Episodic and semantic memory in reports of food intolerance. Applied Cognitive Psychology 13, 451-464.

Knibb, R.C., Booth, D.A., Platts, Armstrong, A.M., R.G., Booth, I.W., \& Macdonald, A. (2000). Consequences of perceived food intolerance for welfare, lifestyle and food choice practices in a community sample. Psychology, Health and Medicine 5(4), 419430.

Knibb, R.C., Smith, D.M., Booth, D.A., Platts, Armstrong, A.M., R.G., Booth, I.W., \& Macdonald, A. (2001). No unique role for nausea attributed to eating a food in the recalled acquisition of sensory aversion for that food. Appetite 36(3), 225-234.

Rona, R.J., Keil, T., Summers, C., Gislason, D., Zuidmeer, L. et al., (2007). The prevalence of food allergy: A meta-analysis. Journal of Allergy and Clinical Immunology 120(3), 638-646.

Royal College of Physicians and British Nutrition Foundation (1984). A Report on Food Intolerance and Food Aversion. Journal of the Royal College of Physicians of London 18(2), 83-123.

Young, E., Stoneham, M.D., Petrukevitch, A., Barton, J., \& Rona, R.A. (1994). Population study of food intolerance. Lancet 343, 1127-1130. 
Table 1. Percentage of interviewees and reports categorised as possibly misdiagnosing their food allergy or intolerance based on a criterion used as a question in the self-assessment tool

\begin{tabular}{llcc}
\hline $\begin{array}{l}\text { Question } \\
\text { number }\end{array}$ & Answer & $\begin{array}{c}\text { People } \\
\%\end{array}$ & $\begin{array}{c}\text { Reports } \\
\%\end{array}$ \\
\hline 1 & No & 77 & 74 \\
2 & No & 13 & 9 \\
\hline & & $\%$ of those answering \\
& & \multicolumn{2}{c}{ 'No’ to Q1 or Q2 } \\
\hline 3a & Yes & 20 & 24 \\
3b & Yes & 27 & 31 \\
3c & Yes & 67 & 74 \\
3a+b+c & Yes & 7 & 7 \\
\hline
\end{tabular}


Appendix

\title{
Might you have a food allergy or intolerance to a food?
}

\author{
[page 1] \\ Millions of people blame foods for illnesses they get (or that their child has \\ had). That is, they believe they have a food allergy or intolerance. Do you (or \\ your child) react badly after eating a food? Do you suspect a food of causing a \\ nasty symptom? If so, you can sort out what's best to do, by answering the \\ following queries.
}

The advice coming from your answers is based on scientific research with hundreds of volunteers who thought that something they ate or drank gave them an unpleasant symptom. (If it's a young child who may have a food allergy or intolerance, then whoever most looks after them can adapt these questions and act on the advice on the child's behalf.)

You may have more than one symptom that a food (or drink) may induce, or you may suspect more than one food. The following questions should be answered for just one symptom, and for just one food you believe is causing it. Go through the questions first for the food and the symptom that matter most.

\section{Question 1}

How many times has consuming the

If you can give an exact number (for example, suspected food or drink been followed by the unpleasant symptom?

"Just once" or "Three times"), then go to Question 2

If you are not sure of the exact number of times it has happened (e.g., your answer is "a few times" or "regularly"), then skip the next page and go on to Question 3 


\section{Question 2 [page 2]}

Can you remember whether or not you were ever able to consume the suspected food or drink and not get this symptom?
If you can't definitely remember whether there was such an occasion or not, go straight to Question 3

If you are quite clear:

EITHER that you did not consume that food or drink on any occasion before this symptom first occurred

$\boldsymbol{O} \boldsymbol{R}$ that you definitely did consume it before the occasion that was first followed by the symptom, then this fits in with your precise answer to Question 1.

Your precision of answers to Questions 1 and 2 is evidence that, in the past as you recall it, the symptom followed the consumption of that food or drink on one or more occasions. Such specific memories indicate that your belief that the food causes the symptom is based on one or more actual experiences. It is not just a guess - for example, from remembering the food or drink and remembering the symptom but without being sure that they ever went together.

With such definite answers to Questions 1 and 2, you do not have to answer any more questions. You have clear evidence that the foodstuff or beverage may be causing you problems. If having this symptom or avoiding that food or drink is bothersome, you should consider getting tested. You should ask your G.P. for a referral for tests for allergy or intolerance in a hospital in your Health region. Note that the tests given by other sorts of practitioners (e.g. hair analyses, bioelectric machines) are not scientifically founded and can give most misleading results. 


\section{Question 3 [page 3]}

If you have followed the instruction to skip here after answering Question 1 or Question 2, it would be useful to think about the answers to the following parts $A, B$ and $C$ of this 3rd question before deciding what to do in future about the food that you suspect.

\section{Question 3A}

Do you sometimes get the symptom without consuming the food / drink?

If you do, this could be evidence that the symptom can be caused by something else beside the food.

The nasty effect may come from another food, or it may have nothing to do with anything specific that you ate or drank. If this symptom is bothersome, it would be wise to ask your GP for some advice other than avoiding that particular food or drink.

If the answer is no, please go on to question 3B

\section{Question 3B}

Do you sometimes consume the suspected food/drink without getting the symptom?

If that's so, this could be evidence that this particular food or drink doesn’t ever cause that symptom. The unpleasant effect may arise from some other food. The suspected food or drink might be interacting with something else that could be tackled. The bad reaction might not come from foods or drinks at all. Consider asking your GP for advice about this symptom which doesn't involve that food or even the diet at all.

If the answer is no, please go on to question 3C 


\begin{tabular}{|c|c|}
\hline $\begin{array}{l}\text { Do you suspect two or three foods of } \\
\text { causing the symptom, or perhaps quite a } \\
\text { number of foods? }\end{array}$ & $\begin{array}{l}\text { foods and you've had the unpleasant } \\
\text { symptom. Yet it's quite possible to be mis- } \\
\text { led by sheer coincidence. Consider the fact } \\
\text { that we usually eat something every few } \\
\text { hours during the day. Therefore, a symptom } \\
\text { that has nothing to do with any food can } \\
\text { occur within some hours or even minutes of } \\
\text { the foods in a meal or snack. So it is easy for } \\
\text { someone very sensible to make a mistake } \\
\text { about what is going on in such a complicated } \\
\text { situation. } \\
\text { It would be advisable for you to consider the } \\
\text { possibility that your symptom may come } \\
\text { from only one of these foods or drinks. It } \\
\text { may even have nothing to do with any of } \\
\text { those particular items. }\end{array}$ \\
\hline \multicolumn{2}{|c|}{$\begin{array}{l}\text { If the symptom is serious enough to take to a doctor, you should consider asking your } \\
\text { GP for advice or treatment. If there is good reason from other cases to suspect } \\
\text { something in the diet or in the environment, you can be referred or go direct to a } \\
\text { hospital clinic for the testing of foods, pollens, dusts etc. that are known to provoke } \\
\text { allergies or other sensitivities. Do not trust the results of hair analyses, bioelectric } \\
\text { machines or other scientifically unfounded tests: the conclusions can be badly } \\
\text { misleading and cause you unnecessary trouble. }\end{array}$} \\
\hline \multicolumn{2}{|c|}{$\begin{array}{l}\text { If your answer is NO to questions } 3 a \text {, b or c then you should also consider going to your } \\
\text { G.P. for a referral for allergy testing, as you have good reason to believe that the co- } \\
\text { occurrence of food and symptom is not a coincidence. }\end{array}$} \\
\hline \multicolumn{2}{|c|}{$\begin{array}{l}\text { If you suspect another food or drink besides the one for which you answered the above } \\
\text { questions, or if you have another symptom that you suspect a food of causing, you can go } \\
\text { back to Question } 1 \text { and review your personal experience of that food and symptom. }\end{array}$} \\
\hline
\end{tabular}


(C) R.C. Knibb \& D.A. Booth, University of Birmingham (UK), May 2000. To be reproduced as a whole only, with permission.

[If you or your doctor or other advisor has any general comment or question about this selfcare advice tool, the Birmingham University Prof. David Booth would be glad to receive a letter. Please note however that advice on individual circumstances cannot be provided.] 